\title{
English Pronunciation Curriculum Model on Reading Assistant SRS: Constructivism View ${ }^{\star}$
}

\author{
Jingjing $\mathrm{Li}^{1}$ \\ Xi'an International Studies University
}

\begin{abstract}
In allusion to the English pronunciation curriculum, with the constructivism theory, and in line with the description of University Teaching Syllabus for English Majors, this paper expounds the integration of Speech Recognition System (SRS), Reading Assistant, and English pronunciation curriculum in depth. This system underlines that student, as the subjective status in learning curriculum, shall make a scientific assessment and give a feedback on new knowledge about the English pronunciation instruction from an objective perspective. The curriculum is designed and assessed reasonably based on the constructivism, computer network and content-based integration with foreign languages to construct a pronunciation-teaching model based on Reading Assistant. Then the curriculum assessment is implemented concretely. It is divided into 5 major modules, including the requirements, knowledge presentation, SRS application approaches, investigation on practice scores, diagnosis and the final test. The curriculum content designed according to the learning effect evaluation is assessed to formulate the appropriate "English pronunciation assessment sheet" and "Assessment sheet on English pronunciation term-end exams". The SRS based on Reading Assistant under the constructivism perspective has important practical value for students' independent study and constructing individual knowledge on English pronunciation learning.
\end{abstract}

\section{Keywords}

Reading assistant $\bullet$ SRS $\bullet$ Constructivism $\bullet$ Curriculum Design $•$ English Pronunciation

\footnotetext{
* Supported by the Research Funding of Xi'an International Studies University (17XWB07)

${ }^{1}$ Correspondence to: Jingjing Li (MA), School of English Studies, Xi'an International Studies University, Xi'an 710128, China. Email: lijingjing@xisu.edu.cn
}

Citation: Li, J., English Pronunciation Curriculum Model on Reading Assistant SRS: Constructivism View. Educational Sciences: Theory \& Practice, 18(5), 1246-1254. http://dx.doi.org/10.12738/estp.2018.5.024 
The objective of college English teaching is to cultivate students' ability to apply English comprehensively and authentically therefore; English pronunciation takes an even more obvious important sight. The instructional quality directly affects students' interval recognition and oral communication abilities. The current English pronunciation curriculums are mostly to train individual phoneme and word with the traditional instruction approaches that "teacher-demonstration and the student-imitation", however, the habit of English pronunciation has been deeply rooted in the heart of students, which makes them impossible to change their usual practice simply by this mode. With the rapid development of computer technology, the speech training software has been widely applied in English learning and teaching approaches. This paper bases itself on the constructivist theory to explore the reformation of English curriculum relying on Reading Assistant SRS, and proposes an operable framework for the design and assessment of English pronunciation class for majors with the help of multimedia-assisted pronunciation instruction.

\section{Nature and objective of English pronunciation curriculum}

The University Teaching Syllabus for English Majors promulgated by the Ministry of Education (MOE) in 2000 clearly specifies that the articulation of students in English majors should be correct with natural tone and smooth speech flow, while further states: "Classroom instruction should insist the learner-centered, and teacherleading mode, ...... we should actively adopt the modern, diversified and all-around instruction mode and positively explore and develop computer-aided instruction based on the existing electrified education equipment". Obviously, the traditional pronunciation teaching mode has been obsolete to dissatisfy the modern demands. The computer technology development has advanced the popularization of multimedia instruction, and the constructivist learning theory has aroused people's wide concern. Computer, multimedia and network information technology act as the cognitive instruments in constructivist learning environment, which can effectively drive the development of students' cognition competence. Consequently, the constructivism learning theory has enlightened us in English pronunciation instruction by three ways: (1) individual-based cognition; (2) interaction-based cooperation; (3) cognition-based scenarios (Chen, 2010). This paper aims to find an integration of constructivism and technology-based way in English pronunciation curriculum design.

\section{Reading assistant SRS}

Reading Assistant, as a kind of SRS developed by the American Scientific Learning Company, takes the language learning theory as basis, to improve the learners' pronunciation competence by imitation and reading aloud and other approaches, further providing in training the integrated language skills such as vocabulary and grammar. When using the system, students should make a self-test based on the benchmark articles with a result of the default article. Each article can be read aloud for 10 times. The system imports the pronunciation practice context to achieve the object imitation. In actual communication activities, the listening skills, speaking skills, reading skills and writing skills do not imply to exchange the thoughts based on isolated factors and words, but on synthetic statements and higher-level discourse units. Isolated factors and word pronunciation in the comprehensive application will have great variations, such as linking, loss of blasting, weakening, and the 
articles included in the system also involve the pronunciations of male and female at all ages. Additionally, the intelligent automatically scoring function in this system ensures the accuracy of pronunciation imitation, the objectivity and controllability of reading process. The students' read-aloud imitation will be evaluated as correct pronunciation, misreading, incapable reading, inaccuracy, etc. respectively, and pinpointed in different colors. When a serious error occurs during the reading imitation process, the system comes to a halt at this time and randomly plays a correct pronunciation to ask the practitioner to repeat it. In addition to the comprehensive assessment on the read-aloud, students also catch sight about the speech rate, the error rate, and the phrases most frequently misread from the system memory after each reading. Tutors can supervise the process of readaloud of students to point out the reading problems at any time. The system is also furnished with reading exercises, including vocabulary, discourse, and paragraph comprehension. While students end in reading, they can continue to do the exercises for further enhancement of the comprehending the articles.

The design of this SRS is well-illustrating the activity theory in designing constructivist learning environments. It emphasized on the appropriateness for analyzing needs, tasks, and outcomes and the interaction of human activity and consciousness within its relevant environmental context. Research in the adoption of technology pronunciation learning autonomy shows the possibility of developing pronunciation autonomy (Yunus, Salehi \& Amini, 2016). Yolanda Joy Calvo Benzies put forward that in the traditional approach's pronunciation teaching class, the main focus is on individual sounds (therefore, only segmental pronunciation was considered); and pronunciation tasks is designed in decontextualized drills whereas in the current approaches, emphasis is expected to be placed on both segmental and suprasegmental and tasks should include aural-oral drills as well as (semi-) communicative practice formats. Therefore, the Reading Assistant SRS resembles the main features of the modern approaches. Furthermore, the system is constructed based on the constructivist instruction model, where students is learner-centered instead of passively knowledge receptors to make a scientific assessment and feedback on the new knowledge and experience from an objective angle by actively practice in the original knowledge system.

\section{Theoretical basis and design rationale}

\section{Theoretical basis}

Constructivism is a major branch of the cognitive theory. Constructivism learning theory advocates to construct a student-centered learning environment with the guidance of teachers, including the four essential elements, i.e. scenario, collaboration, dialogue and semantics construction ( $\mathrm{Si}$ and Zhao, 2013). Learning is a process that involves active construction and not passive acquisition (Duffy and Cunningham, 1996). There are two main approaches in constructivism: cognitive constructivism and social constructivism. The former emphasizes the mind in learning, whereas the latter on the environment and the interaction between learners. The two approaches both underline that the learner learns by constructing their own knowledge and put the learner in the center of learning and teaching. The instruction mode is student-centered and allows teachers play the role of organizer, instructor, assistor and facilitator throughout the instruction process; make use of the scenario, collaboration, dialogue and other environment elements; give full play to students' initiative, 
enthusiasm, and ultimately achieve the goal of effective meaning construction on the current knowledge that students learn. It is obvious in this mode that students are the active constructor of knowledge, teachers are the organizer, instructor and the assistor and facilitator in the semantics construction; knowledge provided in the textbooks will be no longer the content conferred by teachers, but the object of meaning actively constructed by students; the media is used to create scenarios for collaborative learning and knowledge exchange.

Conventional pronunciation teaching promotes teachers' face-to-face instruction and rely heavily on the students' drill. Celce-Murica et.al. advocates a communicative model of pronunciation teaching, which emphasize more on 1) developing the metacognitive knowledge to understand the pronunciation feature they are working to improve, 2) developing perceptual abilities to distinguish the new sounds, 3) making new sounds in controlled practice activities, 4) pronouncing while also focusing on meaning, and 5) developing automatic abilities to pronounce while communicating through communicative practice.

The constructivism-based English teaching mode integrates the information technology, resources and channels with curriculum contents together by computer, multimedia, Internet and other advanced technologies in the process of English instruction to accomplish the tasks of curriculum education (Huang, 2012). This model breaks the traditional classroom sessions and motivates students to learn to proactively discover, acquire and update knowledge, rather than leaning the knowledge itself. This paper builds a "Pronunciation Learning Cognition Model Based on Reading Assistant" on the foundation of constructivism theory, as shown in Fig. 1, with reference to which, the different modules of English pronunciation lectures and the principles of instruction activities are designed. Students will be able to effectively construct the current English pronunciation learning process through coursework, group practice and Reading Assistant SRS.

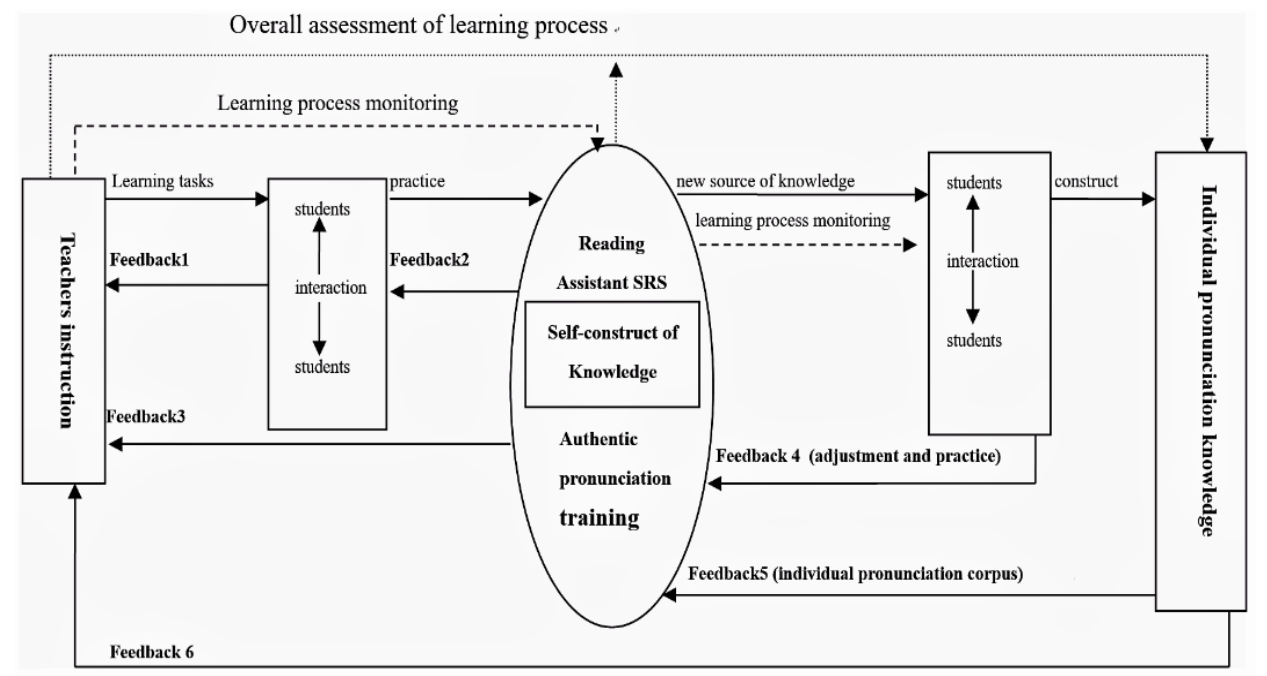

Figure 1. Pronunciation learning cognition model based on reading assistant

The model intuitively reflects the process that learners apply the instruction resources to fulfill their learning tasks autonomously, namely, achieve the self-construction of pronunciation knowledge by the Reading Assistant auto-read system and faculty co-organization and guidance of the curriculum, as well as the interaction 
between students and human-computer collaboration and conversation, thus providing a multi-element bidirection instruction model composed by "teacher - student group - instruction system - student group - ultimate knowledge construction", which shows the essence of constructivism instruction: (1) there is a closed instruction process among teachers, students and system, including professors, assessment and feedback; (2) the system compared students' before and after the practices to form a complete instruction process. (3) The system, students and ultimate pronunciation knowledge are integrated into a complete instruction process. The teachers' coaching, organization and multi-level guidance and organization of the system itself enable the students to break the cognitive disorder of the original knowledge and construct the brand-new pronunciation knowledge; (4) In the whole course, teachers, SRS system, students and construction for ultimate pronunciation knowledge are integrated seamlessly to form an overall process from guidance, collaboration and feedback of supervision. (5) In the whole cognitive model, the SRS serves as a platform for students to construct the knowledge system, and teachers to instruct the students for assessment and surveillance, which effectively addresses a string of problems such as lack of supervision and feedback in the multimedia instruction and overemphasis on student "learning". In the process of model design, teachers and multimedia share the mutual responsibility for the curriculum, while teachers are the most effective organizer for the curriculum, the modern multimedia technology is taken as one of the most effective implementers, fully involving in the whole instruction process. The aim of this design is to ensure the concept that their developing knowledge is shaped by the activities in which they are engaged, the context of the activities, and the enveloping culture (Brown, Collins \& Duguid, 1989). Kim's research shows that the students appreciated the visual feedback received and this visual method did help them improve their pronunciation (Kim, 2012). Luo analyzes the benefits of using recordings outside the classroom to improve students' English pronunciation, and the participants also out-performed those who had only received an in-class approach to English pronunciation. In another word, the new technology is playing an active role in pronunciation learning process unless it is well-integrated with the curriculum design theory (Luo, 2016).

\section{Design rationale}

In the constructivism theory, the curriculum based on the integration of online instruction resources mainly includes contextual design, collaborative learning, and on this basis, the meaning construction that the learners accomplish on the knowledge, the design principles are given as follows: (1) focus on the student-centered mode; (2) emphasize the important role of the "scenario"; (3) emphasize the key role of "collaborative learning"; (4) concern the design of learning environment; (5) exploit various information resources to support "learning"; (6) lay the stress on that the ultimate goal of the learning process is to complete self-knowledge (David \& Roger, 1978). The contemporary constructivist models of learning emphasized that students have important perceptions, knowledge needs to be deep and organized, and learning strategies are critical (Hickey, Kindfield, Horwitz \& Christie, 1999).

In the principle of the curriculum design, the corresponding instruction is designed as follows: (1) analysis of instruction objectives; (2) creation of scenarios; (3) design of information resources; (4) autonomous learning design; (5) collaborative learning environment; (6) learning effect evaluation; (7) design for strengthened exercises. In the new instruction process, the fundamental changes should be facilitated in the instruction content 
to form a new combination of teachers, students, content and media so as to motivate the learning and improve the actual instruction effect. The focus of constructivism instruction design is on the student-centered mode, where students are regarded as cognitive bodies and the active constructor of the knowledge semantics. The teacher only helps and facilitates the students in the knowledge construction, rather than imparts and infuses knowledge to students directly (Wang, 2014). The integration of computer network and English instruction, especially the former, has been two integral parts of the curriculum system. The Reading Assistant based pronunciation cognition model reveals a series of key factors that affect learners' comprehensive capability of pronunciation, including student-centered mode, scenarios and collaborative learning, and computer online instruction, therefore, the concrete implementations of curriculum content, process and results should be projected to fully reflect its design effect.

\section{Concrete implementation of English pronunciation curriculum design and assessment}

\section{English pronunciation curriculum}

Module 1: the requirements and implication of pronunciation curriculum are described to assist students in leading a fluent, clear and intelligible, communicative oral English training. The construction content should be targeted, personalized, and it focus on commonalities, based on which the Reading Assistant auto-voice reads, post-class speech counseling, speech training and demonstration, etc. are set additionally to help students construct personal pronunciation knowledge.

Module 2: the English pronunciation knowledge in various blocks can be explained with the basic concepts of syllables, sounds and rhythms as entry points, focus on vowels, consonants, and phonetic alphabets; intersperse such explanation with the rhythm of English speaking, speech intonation, including the function of tone; help students consciously imitate, correctly improve the fluency develop good oral expression habits, in order to achieve the goal of effective communication.

Module 3: the functions and approaches of adopting Reading Assistant SRS are introduced to the students and the students' self-learning competence is further emphasized. The human-computer interaction is adopted to provide personalized instructions, achieving one-on-one teaching and learning relationship. After the selfdetermination grading, it helps the students gradually finish the process of individual speech training about how to perform the speech intonation training according to the article grades as indicated, how to replay, correct the pronunciation in the real scenarios, thus achieving the construction of pronunciation knowledge.

In the principle of the constructivism curriculum design — autonomous learning design - collaborative learning environment - strengthened exercise design — is required, according to the different instruction modes as chosen, to make diverse designs on students' autonomous learning, around which to make a further study and it further aims to create a variety of scenarios which allows students freely access to learn in their individual style (Tang and $\mathrm{Xu}, 2013$ ). Collaborative learning environment requires that based on individual autonomous learning, teachers organize and lead the group discussions and consultations so as to further improve and deepen 
the meaning construction of topics. In constructivist learning environments, group discussion is considered critical for understanding. In fact, it has been argued that learning is a "social, communicative and discursive process, inexorably grounded in talk," echoing the importance of dialogue voiced by Freire and Vygotsky. Consequently, the curriculum should also include the following two modules:

Module 4: the Gordian knots in students' learning process are identified in accordance with the content of classroom instruction, students' classroom digestion, Reading Assistant SRS practice feedback, extracurricular speech practice Q\&A and so on, and some exercises for individual student are designated for key training chapters, randomly to adjust or urge students to improve their exact match based on individual performance scores.

Module5: the typical records and the soundtracks are regularly displayed in the classroom to compare with the system originals, and students are required to carefully analyze and correct errors mutually. The diagnostic tests are periodically conducted on speech practice default by SRS to help students find the deficiencies in their own learning process about phonetics.

\section{Curriculum assessment}

The curriculum is assessed by the learning effect assessment designed in the constructivism instruction model, where it is required to include the individual assessment of team and individual self-assessment of students around three aspects: independent learning capability; contribution made in the collaborative learning process; whether to measure up the requirements for the meaning construction. Teachers should incorporate the formative and authentic assessments on the students. Formative assessment is based on the instruction process with an object of one-time formative assessment as the full content at a certain stage of the construction process. The authentic assessment focuses on collection of performance information of students who are engaged in real learning activities, by which to examine their competences to apply knowledge and skills in real scenarios. Students in the English pronunciation Curriculum are assessed as shown in Table 1.

Table 1

Assessment Sheet for English Pronunciation Curriculum

\begin{tabular}{|c|c|c|c|}
\hline Order & Content of Assessment & Ratio & Reference \\
\hline 1 & $\begin{array}{l}\text { In-class response and other designed } \\
\text { class activities }\end{array}$ & $10 \%$ & \multirow{5}{*}{$\begin{array}{l}\text { The fist five stages are the average score of the } \\
\text { achievements by the students. }\end{array}$} \\
\hline 2 & $\begin{array}{c}\text { Personal use of Reading Assistant and } \\
\text { the system assessment }\end{array}$ & $20 \%$ & \\
\hline 3 & $\begin{array}{l}\text { The performance of the sharing } \\
\text { learning experience }\end{array}$ & $20 \%$ & \\
\hline 4 & Teachers' assessment & $10 \%$ & \\
\hline 5 & Reading Assistant interim assessment & $15 \%$ & \\
\hline 6 & Final exam & $20 \%$ & $\begin{array}{l}\text { The average score of both Chinese and foreign } \\
\text { teachers }\end{array}$ \\
\hline 7 & The teachers' overall evaluation & $5 \%$ & $\begin{array}{l}\text { Treat scores for student's participation in team } \\
\text { activities }\end{array}$ \\
\hline
\end{tabular}


Table 2

Assessment Sheet for Term-End Exams of English Pronunciation Curriculum

\begin{tabular}{lccccc}
\hline Items & Vowels and Consonants & Words & Sentence & Passage & Impromptu speech \\
\hline Ratio & $20 \%$ & $20 \%$ & $25 \%$ & $25 \%$ & $10 \%$ \\
\hline
\end{tabular}

When teachers develop the content of assessment on the term-end exams, in order to make it more comprehensive, more objective, the types of quizzes for term-end exams are determined with reference to the Syllabus of the National Test for Oral English Majors-Band 4, University Teaching Syllabus for English Majors and various types of classic curriculums on English pronunciation. The test in pronunciation textbook is divided into 5 parts, i.e. phoneme recognition, words reading, single sentence reading, text reading and impromptu speech, as shown in Table 2.

The assessment process uses Likert five-level scale, i.e. the native-like, good, fairly good, poor, and unacceptable, in this way, which can objectively reflect and diagnose the problems, occurred after students' construction of the pronunciation knowledge.

In a word, in accordance with the constructivism instruction theory, the curriculum assessment process should focus on the independent learning capability, where individual use of Reading Assistant and systematic feedback, the performance of the exchange of learning achievements, the phased test results in Reading Assistant and others are a comprehensive assessment designed for students' abilities to learn independently. Research (Espasa and Meneses, 2009) reports that feedback offered during the continuous assessment process is the most widespread form of feedback in online classrooms. This assessment approach should not only make the students unburden any pressure, but also be objective and accurate. It is indispensable to design the termend assessment and teachers' assessment on the students' phonetics and the comprehensive assessment of the teachers and other parts to ensure an objective, definite and comprehensive assessment on students.

\section{Conclusion}

Constructivism-based construction model has been gradually developed with the popularity of online education; however, any model with more complete and rigorous theoretical system and highly operability has not yet emerged. Classroom observation, for instance, can best be performed to further examine whether they can apply in pronunciation instruction and the situations under which language learners can best learn the pronunciation characteristics. The disagreed comprehension of principles makes the teachers plunge into more troubles in the process of instruction design, so that it is urgent need for a prescription solution to streamline the curriculum implementation. Autonomous learning is an ultimate goal of university English instruction on the premise of automated instruction where the humanistic theory and the constructivism theory are applied in practice to help students learn from single theory enlightenment to self-cognition, so that students enable selfconstruction of learning mode and goal. 


\section{References}

Brown, J. S., Collins, A., \& Duguid, P. (1989). Situated cognition and the culture of learning. Educational Researcher, 18(1), 32-42. https://dx.doi.org/10.3102/0013189X018001032

Chen, J. L. (2010). The integration of computer and networks into foreign language curriculum-a research based on college English reform shanghai, china, Shanghai Foreign Language Education Press.

David, J., \& Roger, J. (1978). Cooperative, competitive and individualistic learning. Journal of Research and Development in Education, 12(1), 1-15.

Duffy, T. M., \& Cunningham, D. J. (1996). 7. Constructivism: Implications for the Design and Delivery of Instruction. In The handbook of research for education and technology, 171(4), 170-198.

Espasa, A., \& Meneses, J. (2010). Analysing feedback processes in an online teaching and learning environment: an exploratory study. Higher Education, 59(3), 277-292. http://dx.doi.org/10.1007/s10734009-9247-4

Hickey, D. T., Kindfteld, A. C., Horwitz, P., \& Christie, M. A. (1999). Advancing educational theory by enhancing practice in a technology-supported genetics learning environment. Journal of Education, 181(2), $25-55$.

Huang, W. (2012). The College English Teaching Informatization: A Constructivism, Education and Vocation, 8, 101-102. http://dx.doi.org/10.13615/j.cnki.1004-3985.2012.08.008

Kim, A. Y. (2012). Investigating the effectiveness of computer-assisted language learning (CALL) in improving pronunciation: A case study, Multimedia-Assisted Language Learning, 15(3), 11-33.

Luo, B. (2016). Evaluating a computer-assisted pronunciation training (CAPT) technique for efficient classroom instruction. Computer Assisted Language Learning, 29(3), 451-476.

SI, X. Z., \& Zhao, H. Y. (2013). College English course design: A perspective of constructivist teaching model [J]. Computer-Assisted Foreign Language Education, 3, 014.

Tang, Y. Z., \& Xu, X. F. (2013). The design of web-based education: Constructivism. Education and Vocation, 9, 164-165. http://dx.doi.org/10.13615/j.cnki.1004-3985.2013.09.030

Wang, W. H. (2014). problems and solutions to English education: Constructivism. China Adult Education, 4, $145-147$.

Yunus, M. M., Salehi, H., \& Amini, M. (2016). EFL teachers' cognition of teaching English pronunciation techniques: A mixed-method approach. English Language Teaching,9(2), 20-42. http://dx.doi.org/10.5539/elt.v9n2p20 